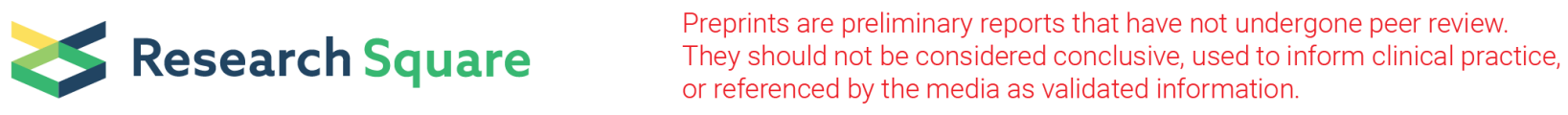

\title{
Descriptive Analysis of Reported Adverse Events Associated with Antiobesity Medications Using FDA Adverse Event Reporting System (FAERS) Databases 2013-2020
}

Abdulrahman Alsuhibani ( $\sim$ aas.web7@gmail.com)

University of Cincinnati James L Winkle College of Pharmacy https://orcid.org/0000-0003-4852-1166

Marwan Alrasheed

University of Cincinnati James L Winkle College of Pharmacy

Musaab Gari

University of Cincinnati James L Winkle College of Pharmacy

Ana Hincapie

University of Cincinnati James L Winkle College of Pharmacy

Jianfei Guo

University of Cincinnati James L Winkle College of Pharmacy

Research Article

Keywords: Obesity, Antiobesity medications, Federal Adverse Events Reporting System, Adverse events, Cardiovascular disease.

Posted Date: June 28th, 2021

DOI: https://doi.org/10.21203/rs.3.rs-628129/v1

License: (c) (i) This work is licensed under a Creative Commons Attribution 4.0 International License. Read Full License 


\section{Abstract \\ Background}

Obesity is a globally growing health problem, and its treatment has been challenging. The usage of antiobesity medications (AOMs) has been associated with severe adverse events (AEs). Spontaneous reports of AOMs can present detailed information about AEs occurring after the time of marketing. Several AOMs have been withdrawn from the market owing to documented AEs.

\section{Objective}

To estimate and characterize the frequency of AEs attributable to the use of the AOMs between January 2013 and June 2020.

\section{Setting:}

US FDA Adverse Event Reporting System (FAERS) between January 01, 2013, and June 31, 2020,

\section{Methods}

A retrospective, descriptive analysis was conducted to analyze all major reported AEs including death, life-threatening, hospitalization, disability, and required intervention or congenital anomaly related to AOMs. The total numbers of AEs reports, cases, adverse reactions and outcomes were calculated for each medication, and patients' mean age and gender were reported.

\section{Results}

We found a total of 18,675 unique AEs reports associated with AOMs used for 15,143 patients. The mean age was 49.8 years [SD 1.83], while most patients were female adults (73.4\%). The main AEs of the safety reports were nausea, headache, cardiovascular diseases, dizziness, drug ineffectiveness, acute kidney failure/ kidney injury, and dry mouth. The FAERS database had 21,229 unique outcomes involving AOMs use, including 1,039 deaths (fatality ratio of $4.9 \%$ of all analyzed reports), 1,613 (7.6\%) life-threatening events, 7,426 (35\%) hospitalizations, and 1,249 (5.9\%) disability cases. Phentermine/topiramate fatal cases represent $6 \%$ of the overall medication's reported AEs. The cardiovascular AEs were 542 reports (31\%) for phentermine, 402 reports ( $23 \%)$ for liraglutide, 381 reports $(22 \%)$ for phentermine/topiramate.

\section{Conclusion}

Although several AOMs have been withdrawn from the market and replaced with new ones, the utilization of the AOMs is widespread; the FAERS database's analysis revealed many serious AEs in the type of cardiovascular diseases and kidney complications attributable to the use of the AOMs. Therefore, it is necessary to continue and systematically monitor AOMs' safety to help optimize their use.

\section{Impacts On Practice}

Using the FAERS database, we found that nausea and vomiting were the most frequent events associated with the AEs reported outcomes.

The study exhibited that $35 \%$ of the reviewed $\mathrm{AE}$ reports required an initial or prolonged hospitalization.

The FAERS database's analysis revealed many serious AEs in the type of cardiovascular diseases and kidney complications attributable to the use of the antiobesity medications.

\section{Introduction}

Obesity is defined as a body mass index (BMI) of $\geq 30 \mathrm{~kg} / \mathrm{m}^{2}$ and is caused by an imbalance between energy intake and expenditure. It has affected nearly 100 million adults in the United States (US), and it is universally identified as the fastest-growing public health challenge in the world [1-3]. It is a global health crisis with detrimental impacts on the body systems, resulting in an exacerbated disease state.

Education and modifications to the obesogenic environment are effective long-term goals for preventing obesity; however, sustainable weight loss is difficult to be achieved through lifestyle changes in the form of exercise or diet [4], and surgical or pharmacological treatment is required for those who are already obese. One thriving modality aimed at mitigating obesity and enhancing survival is bariatric surgeries. However, because of some concerns regarding surgical complications and perioperative mortality, guidelines recommend reserving these procedures for morbidly obese patients [5-8].

Another approach to treat obesity is by using antiobesity medications (AOMs) as an adjunct therapy for those who fail to achieve a significant weight loss only through lifestyle modification. These medications can reduce body weight by decreasing food consumption or absorption, or increasing energy expenditure [9]. During the last decade, most of the new generation of the AOMs have shown encouraging tolerability profiles with a modest increase in the prevalence of use [10]. However, the shortfall of prolonged follow-up may confound the accurate ascertainment of risk-benefit; many of the AOMs that were 
presented as the solution to obesity have been withdrawn from the market during the last two decades owing to reports of multiple major adverse events (AEs) associated with them [11].

High-profile market withdrawals of AOMs justify the concerns about more serious AEs associated with the new generation of AOMs. In 1997, two AOMs (fenfluramine and dexfenfluramine) were withdrawn from the market due to concerns over valvular heart disease and pulmonary hypertension [12]. In 2010, the Food and Drug Administration (FDA) asked Abbott Laboratories to pull the antiobesity medication sibutramine from the market in view of clinical trial data showing an increased risk for cardiovascular disease (CVD), specifically heart attack and stroke in high-risk cardiac patients [13, 14]. Eventually, on February 13,2020 , the FDA requested a withdrawal of another AOM (lorcaserin) because a safety clinical trial revealed a potential risk of an increased cancer occurrence among lorcaserin users [15].

The available literature suggests the need for further investigation regarding the frequency of AEs associated with AOMs in order to assess the potential negative consequences of their use. The spontaneous $\mathrm{AE}$ reports are considered a highly valuable source of information about serious, rare, or unknown $\mathrm{AEs}$ associated with medication use that was not recognized at the time of marketing [16]. Therefore, in the present study.

\section{Aim of the study}

We aimed to explore and characterize the AEs associated with the use of AOMs available in the US from the first quarter of 2013 to the end of the second quarter of 2020.

\section{Ethics approval}

This work was conducted in accordance with the ethical standards laid out in the Declaration of Helsinki, 1964. Because this study was an observational study using a global open database (FAERS) with anonymized information and not involving treatment intervention or collection of human samples, informed consent was exempted.

\section{Methods}

\section{Study design and source data}

This study was designed as a retrospective, descriptive analysis of all reported AEs associated with AOMs using the FDA Adverse Event Reporting System (FAERS) from January 01,2013 , to June 30, 2020. The database includes information on AEs and medication error reports submitted by healthcare professionals, consumers, and manufacturers to the FDA. FAERS database is meant to assist the FDA's postmarketing safety surveillance program for medications and therapeutic biologic products. The informatic formation of the FAERS database complies with the international safety reporting guidance declared by the International Conference on Harmonisation (ICH E2B) [17]. Medication errors and adverse events are coded to terms in the Medical Dictionary for Regulatory Activities terminology.

\section{Measures}

All of the adverse event reports of the studied medications during the study period were included and we included all patients aged $\geq 18$ years who have an AE report linked to one of the six major FDA approved AOMs listed in Table 1 [18]. We searched the database using both brand and generic names for every medication, based on the primary adverse event drug name. All adverse events were extracted from the column of "preferred_term or PT" in the FAERS database, and we did include all adverse event terms extracted from FAERS and did not exclude any terms that may not match the Medical Dictionary for Regulatory Activities (MedDRA) preferred terms. To exclude other use indications, we require either the indication to be for antiobesity or using the brand name of the drugs. For this study, we also grouped some adverse events into several categories, such as CVD (cardio, heart, vascular, arithmetic, etc.), cancer (malignant, neoplasm, etc.), kidney injury (kidney, renal, AKF, etc.), and so on. The total numbers of AOMs adverse event reports, cases, adverse reactions and outcomes were calculated by adding the data for all years for each AOM. These adverse event outcomes are not jointly exclusive, so the sum of the percentages exceeds 100 percent as a patient can encounter more than one of these outcomes simultaneously. All analyses were performed using SAS Version 9.4 (SAS Institute Inc., Cary, NC, USA) and Microsoft Excel 2020 (Microsoft Corporation, Redmond, WA, USA).

\section{Results}

Using FAERS in the period between the first quarter of 2013 and the second quarter of 2020, we found 18,675 unique adverse event reports submitted to FAERS and associated with AOMs use, representing 15,143 patients, as one patient might have more than one report. Figure 1 shows the trends of AOMs reports over the study period, considering that only the first two quarters of 2020 are included. Among all reports, the mean age was 49.8 years [SD 1.83], while most patients were female (accounted for $73.4 \%$ of all cases).

The leading events associated with the AEs reported outcomes (Fig. 2) are nausea and vomiting with a total of 3,691 reports (Table 2), followed by dizziness and headache, drug ineffectiveness or weight increased, CVD, acute kidney failure (AKF) /kidney injury, diarrhea, constipation, insomnia, anxiety, dry mouth, and paraesthesia. The cardiovascular AEs were 542 reports (31\%) for phentermine, 402 reports (23\%) for liraglutide, 381 reports (22\%) for phentermine/topiramate, 177 reports (10\%) for orlistat, and 135 reports ( $8 \%$ ) for lorcaserin (Table 2 ). It is apparent from this table that compared to the other AOMs, phentermine, phentermine/topiramate, and liraglutide had a relatively high number of reporters associated with AKF/kidney injury: $38 \%$, $23 \%$, and $17 \%$, respectively. Top AEs associated with using naltrexone/bupropion drug were nausea and vomiting (27\%), dizziness and headache (22\%), insomnia (19\%), and anxiety (17\%). 
Table 1

Antiobesity medications marketed in the United States from 1980-2020 1-4

\begin{tabular}{|c|c|c|c|}
\hline Generic name & Brand name & FDA approval date & Manufacturer \\
\hline \multirow[t]{2}{*}{ Orlistat } & Xenical ${ }^{\circ}$ & 04/23/1999 & CHEPLAPHARM \\
\hline & Alli® & 02/07/2007 & GLAXOSMITHKLINE CONS \\
\hline \multirow[t]{2}{*}{ Lorcaserin $^{a}$} & Belviq® ${ }^{\circledR}$ & $06 / 27 / 2012$ & EISAI INC \\
\hline & Belviq-XR® & $07 / 15 / 2016$ & EISAI INC \\
\hline \multirow[t]{2}{*}{ Phentermine } & Adipex-P® & $10 / 22 / 1980$ & TEVA \\
\hline & Lomaira ${ }^{\circledR}$ & $09 / 12 / 2016$ & AVANTHI INC \\
\hline Phentermine / Topiramate & Qsymia ${ }^{\circledR}$ & 07/17/2012 & VIVUS \\
\hline Naltrexone / Bupropion & Contrave ${ }^{\circledR}$ & $09 / 10 / 2014$ & NALPROPION \\
\hline Liraglutide & Saxenda ${ }^{\circledR}$ & $12 / 23 / 2014$ & NOVO \\
\hline \multicolumn{4}{|c|}{${ }^{a}$ Withdrawn from the market in February 2020.} \\
\hline \multicolumn{4}{|l|}{ References } \\
\hline \multicolumn{4}{|c|}{ 1. Srivastava G, Apovian CM. Current pharmacotherapy for obesity. Nat Rev Endocrinol. 2018;14(1):12-24. doi:10.1038/nrendo.2017.122 } \\
\hline \multicolumn{4}{|c|}{ 2. Drugs@FDA: FDA-Approved Drugs. https://www.accessdata.fda.gov/scripts/cder/daf/. Accessed December 1, 2020.} \\
\hline \multicolumn{4}{|c|}{$\begin{array}{l}\text { 3. Daneschvar HL, Aronson MD, Smetana GW. FDA-Approved Anti-Obesity Drugs in the United States. Am J Med. 2016;129(8):879.e1-6. } \\
\text { doi:10.1016/j.amjmed.2016.02.009 }\end{array}$} \\
\hline \multicolumn{4}{|c|}{$\begin{array}{l}\text { 4. U.S. GAO - Obesity Drugs: Few Adults Used Prescription Drugs for Weight Loss and Insurance Coverage Varied. https://www.gao.gov/products/GAO-19- } \\
\text { 577. Accessed January 5, } 2021 \text {. }\end{array}$} \\
\hline
\end{tabular}

Table 2

The most commonly reported adverse events associated with antiobesity medications. Using FAERS databases 2013-2020

\begin{tabular}{|c|c|c|c|c|c|c|c|c|c|c|c|c|}
\hline Drug Names & $\begin{array}{l}\text { Nausea } \\
\text { and } \\
\text { Vomiting } \\
(\%)\end{array}$ & 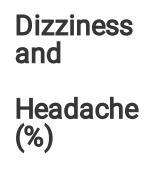 & $\begin{array}{l}\text { Drug } \\
\text { Ineffective/ } \\
\text { Weight } \\
\text { Increased } \\
\text { (\%) }\end{array}$ & $\begin{array}{l}\text { CVD* } \\
(\%)\end{array}$ & $\begin{array}{l}\text { AKF*/ } \\
\text { Kidney } \\
\text { Injury } \\
(\%)\end{array}$ & $\begin{array}{l}\text { Diarrhea } \\
(\%)\end{array}$ & $\begin{array}{l}\text { Constipation } \\
(\%)\end{array}$ & $\begin{array}{l}\text { Insomnia } \\
\text { (\%) }\end{array}$ & $\begin{array}{l}\text { Anxiety } \\
(\%)\end{array}$ & $\begin{array}{l}\text { Dry } \\
\text { Mouth } \\
\text { (\%) }\end{array}$ & $\begin{array}{l}\text { Paraesthesia } \\
\text { (\%) }\end{array}$ & C \\
\hline Orlistat & $101(3)$ & $147(4)$ & 231 (9) & $\begin{array}{l}177 \\
(10)\end{array}$ & $\begin{array}{l}160 \\
(12)\end{array}$ & $174(18)$ & $34(4)$ & $20(3)$ & $24(3)$ & $5(1)$ & $25(5)$ & 1 \\
\hline Lorcaserin & $283(8)$ & $906(26)$ & 864 (33) & $\begin{array}{l}135 \\
(8)\end{array}$ & $69(5)$ & $67(7)$ & 109 (12) & $69(9)$ & $51(7)$ & $\begin{array}{l}87 \\
(14)\end{array}$ & $28(6)$ & 3 \\
\hline Phentermine & $818(22)$ & $793(22)$ & $423(16)$ & $\begin{array}{l}542 \\
(31)\end{array}$ & $\begin{array}{l}502 \\
(38)\end{array}$ & $205(21)$ & $281(31)$ & $312(40)$ & $\begin{array}{l}298 \\
(39)\end{array}$ & $\begin{array}{l}267 \\
(43)\end{array}$ & 179 (37) & 5 \\
\hline $\begin{array}{l}\text { Phentermine/ } \\
\text { Topiramate }\end{array}$ & 377 (10) & $416(12)$ & $302(11)$ & $\begin{array}{l}381 \\
(22)\end{array}$ & $\begin{array}{l}307 \\
(23)\end{array}$ & $106(11)$ & $121(13)$ & $194(25)$ & $\begin{array}{l}184 \\
(24)\end{array}$ & $\begin{array}{l}133 \\
(21)\end{array}$ & $138(29)$ & 2 \\
\hline $\begin{array}{l}\text { Naltrexone/ } \\
\text { Bupropion }\end{array}$ & $\begin{array}{l}1005 \\
(27)\end{array}$ & 767 (22) & $322(12)$ & $\begin{array}{l}128 \\
(7)\end{array}$ & $59(4)$ & $142(14)$ & $117(13)$ & 149 (19) & $\begin{array}{l}127 \\
(17)\end{array}$ & $\begin{array}{l}88 \\
(14)\end{array}$ & $47(10)$ & 1 \\
\hline Liraglutide & $\begin{array}{l}1107 \\
(30)\end{array}$ & $511(14)$ & 505 (19) & $\begin{array}{l}402 \\
(23)\end{array}$ & $\begin{array}{l}230 \\
(17)\end{array}$ & $294(30)$ & $242(27)$ & $44(6)$ & $82(11)$ & $46(7)$ & $64(13)$ & $\begin{array}{l}6 \\
(\vdots\end{array}$ \\
\hline TOTAL & 3691 & 3540 & 2647 & 1765 & 1327 & 988 & 904 & 788 & 766 & 626 & 481 & 1 \\
\hline
\end{tabular}

*CVD, cardiovascular disease. AKF, acute kidney failure.

The FAERS database had 21,229 unique reported outcomes involving the usage of AOMs. This includes 7,426 (35\%) initial or prolonged stay hospitalization as the most frequently reported outcome, 1,039 deaths (4.9\% of all reports had the outcome of death), 1,613 (7.6\%) life-threatening events, 1,249 (5.9\%) disability, 671 (3.2\%) congenital anomaly, and 517 (2.4\%) required intervention to prevent permanent impairment/damage, and (41\%) as other outcomes. Figure 3 displays the trends of the type of hospitalization associated with AOMs, and Table 3 shows the number and percentage for the reason of hospitalization related to each of the AOMs. Death and life-threatening outcomes represented $15 \%$ of the documented serious AEs associated with phentermine/topiramate medication use, $14 \%$ of liraglutide use, and $13 \%$ of lorcaserin and phentermine use (Table 3 ). The largest number of fatal cases was reported for phentermine $(n=331)$, followed by liraglutide $(n=217)$ and phentermine/topiramate $(n=174)$. 
Table 3

Type of hospitalization associated with antiobesity medications. Using the FDA's Adverse Event Reporting System (FAERS) database 2013-2020.

\begin{tabular}{|c|c|c|c|c|c|c|c|}
\hline Drug Names & $\begin{array}{l}\text { Hospitalization - Initial } \\
\text { or Prolonged }\end{array}$ & $\begin{array}{l}\text { Life- } \\
\text { Threatening }\end{array}$ & Death & Disability & $\begin{array}{l}\text { Congenital } \\
\text { Anomaly }\end{array}$ & $\begin{array}{l}\text { Required Intervention to Prevent } \\
\text { Permanent Impairment/Damage }\end{array}$ & Other \\
\hline Orlistat (\%) & 835 (39) & $152(7)$ & $89(4)$ & $104(5)$ & $56(3)$ & $44(2)$ & $\begin{array}{l}841 \\
(40)\end{array}$ \\
\hline Lorcaserin (\%) & 945 (37) & $193(8)$ & $\begin{array}{l}137 \\
(5)\end{array}$ & $171(7)$ & $44(2)$ & $39(2)$ & $\begin{array}{l}1004 \\
(40)\end{array}$ \\
\hline Phentermine (\%) & 2452 (37) & $481(7)$ & $\begin{array}{l}331 \\
(5)\end{array}$ & $362(5)$ & $237(4)$ & $175(3)$ & $\begin{array}{l}2627 \\
(39)\end{array}$ \\
\hline $\begin{array}{l}\text { Phentermine/Topiramate } \\
\text { (\%) }\end{array}$ & 962 (32) & $260(9)$ & $\begin{array}{l}174 \\
(6)\end{array}$ & $262(9)$ & $176(6)$ & $98(3)$ & $\begin{array}{l}1114 \\
(37)\end{array}$ \\
\hline $\begin{array}{l}\text { Naltrexone/Bupropion } \\
\text { (\%) }\end{array}$ & $804(30)$ & $151(6)$ & $91(3)$ & $163(6)$ & $39(1)$ & $48(2)$ & $\begin{array}{l}1403 \\
(52)\end{array}$ \\
\hline Liraglutide (\%) & $1428(34)$ & $376(9)$ & $\begin{array}{l}217 \\
(5)\end{array}$ & $187(4)$ & 119 (3) & $113(3)$ & $\begin{array}{l}1725 \\
(41)\end{array}$ \\
\hline TOTAL (\%) & $7426(35)$ & $1613(7.6)$ & $\begin{array}{l}1039 \\
(4.9)\end{array}$ & $\begin{array}{l}1249 \\
(5.9)\end{array}$ & 671 (3.2) & $517(2.4)$ & $\begin{array}{l}8714 \\
(41)\end{array}$ \\
\hline
\end{tabular}

\section{Discussion}

A retrospective descriptive study of the AOMs' adverse events from 2013 through 2020 was conducted using FAERS data in the large US pharmaceutical market. Due to clinical trial studies' inherent limitations, such as limited follow-up duration, stringent design, and relatively small sample size, the spontaneous reporting system (SRS) has been used in pharmacovigilance for safety assessment of a suspected drug's AEs. Furthermore, SRS plays a integral part in signal identification, and the FDA has developed the FAERS database for postmarketing surveillance to monitor the safety of drugs and improve public health [19]. This study aimed to describe the most common AEs and investigate previously unreported potential AEs associated with using the AOMs.

To our knowledge, this is the first study that has systematically analyzed AEs reported for AOMs located in a nationally representative database for over a 7year period. Over $73 \%$ of the reported AEs were for female adults, and that is consistent with previous studies that analyzed global AE reporting patterns of the AOMs [20], [21]. However, we cannot infer whether this can be explained by the increased risk of the incidence of AEs in this population. Drug ineffectiveness, dizziness, headache, nausea, vomiting, and diarrhea were among the most frequently reported AEs for all reports recorded in the FAERS database through 2002 [22], and that is consistent with our findings. The percentage of cardiovascular and AKF/ kidney injury AEs were sizable among phentermine, liraglutide, and phentermine/topiramate users (Table 2).

For liraglutide, which is the only injectable formulation of the AOMs, many AEs of the type gastrointestinal disorders, cancer, and CVD were found. A relatively high rate of death was associated with using liraglutide compared to the other studied medications. A previously published meta-analysis stated that the discontinuation rate due to side effects was the highest among liraglutide users compared to all FDA-approved AOMs [23]. Additionally, a relatively high percentage of disability reports and common gastrointestinal disorders were at the top of the AEs associated with naltrexone/bupropion medication.

Unlike the other medications, orlistat works by decreasing fat absorption, while the other five medications work mainly through CNS pathways that either enhance satiety or reduce appetite. This explains why a large number of diarrhea, renal complications, and drug ineffectiveness AEs were reported with

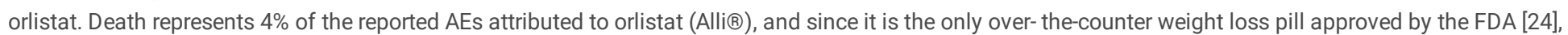
the marketing authorization holder should further investigate the fatal cases associated with using this medication.

Phentermine antiobesity monotherapy is approved for adults for 90-day use and contraindicated in cardiovascular disease patients [25]. It is still the most commonly prescribed AOM in the USA and worldwide, except in the European Union due to its potential adverse effects [26]. From the data shown in Table 2, it is apparent that CVD, AKF/kidney injury, paraesthesia, dry mouth, constipation, and insomnia are highly prevalent among phentermine and phentermine/topiramate users, which is consistent with previous studies [27-29]. Figure 3 reveals a considerably high frequency of the congenital anomaly type of hospitalization associated with phentermine/topiramate. A fetal safety issue and teratogenicity concerns related to phentermine/topiramate use was expressed by the FDA owing to the risk of increased oral clefts. Consequently, women of childbearing age are advised on contraceptive planning before using this medication [30-32].

Drug ineffectiveness, dizziness, headache, and dry mouth were among the most common AEs associated with lorcaserin. Compared to the other medications, the CVD-related AEs were relatively low (8\%) as the medication showed a low rate of major cardiovascular events in previously published studies [25, 30, 33]. In February 2020, the drug was withdrawn from the market over the potential risk of an increased cancer occurrence. Our analysis revealed that cancer reports denote less than $0.9 \%$ of the overall lorcaserin submitted reports and represent $16 \%$ of the overall cancer reports associated with the studied medications, considering that not the only primary suspected medications were included. Rekha Kumar and Donna Ryan wondered whether lorcaserin withdrawal, owing to a numerical imbalance in the cancers occurring in a large, 12,000 participants clinical trial, has left more questions than answers. Ascertainment bias was among many concerns that led them to request a full disclosure of more information around the lorcaserin/cancers potential risk association [34].

The majority of serious AEs were found for phentermine, liraglutide, phentermine/topiramate and they were of the type 'cardiac' and 'renal' disorders. The proper use of medication through following the pharmacist's or the physician's instructions can significantly impact avoiding such undesirable effects. To 
ascertain whether these findings have contributed to detecting new AE signals or merely affirming existing knowledge, conducting comparative studies of the reported $A E$ information with the $A E s$ posted on the official product label are required.

These data must be interpreted with caution because there is no ultimate proof of the causal relationship between exposure to a drug and the reported event. Furthermore, because of the duplicate and incomplete reports (unknown denominator), the incidence of AEs cannot be estimated using FAERS data. Consequently, since we did not limit our analysis to the only primary suspected medications, the values only provide safety signals and do not denote a real risk. Additionally, there is a potential for bias based on physician preference when prescribing the appropriate choice of the AOM for a patient or when reporting the AE. Besides, comorbidities or concomitant drugs might confound the association between a drug and an AE [35]. Also, some medications have other uses that might confound the analysis, particularly liraglutide which is an increasingly common medication used for type 2 diabetes mellitus [36]. To overcome this limitation, we require either the indication to be for antiobesity or using the brand name of the medication. Ultimately, these limitations may lead to an inflation of the risks attributable to the AOMs.

\section{Conclusions}

Given the variation between individuals in their response to the AOMs, these medications' pharmacological utilization continues to be a challenge; as such, it is essential to continue and systematically observe AOMs' safety to optimize their use. Using the FAERS database, we found that nausea and vomiting were the most frequent events associated with the AEs reported outcomes. Moreover, more severe AEs in the type of CVD, acute kidney failure (AKF) /kidney injury were among the most commonly reported AEs. Finally, this study revealed that $35 \%$ of the reviewed AE reports required an initial or prolonged hospitalization. However, Long-term data and cohort studies are required to validate these results and further explore the safety profile of AOMs.

\section{Declarations}

\section{Funding}

This research did not receive any specific grant from funding agencies in the public, commercial, or not-for-profit sectors.

\section{Conflict of interest}

The authors have no commercial associations that might be a conflict of interest concerning this article.

The authors Abdulrahman Alsuhibani, Marwan Alrasheed, Ana Hincapie, and Jeff Jianfei Guo have indicated that they have no conflicts of interest with regard to the content of this article.

\section{Author contributions}

Abdulrahman Alsuhibani carried out the literature review, statistical analyses, manuscript drafting, manuscript editing, and manuscript revision. Marwan Alrasheed participated in statistical analyses and manuscript revision. Musaab Gari participated in manuscript editing and revision. Ana Hincapie carried out the study design and manuscript revision. Jeff Jianfei Guo participated in study design and data collection, manuscript revision, and coordination. All authors read and approved the final manuscript.

\section{Funding}

This research did not receive any specific grant from funding agencies in the public, commercial, or not-for-profit sectors.

\section{Ethics approval}

This work was conducted in accordance with the ethical standards laid out in the Declaration of Helsinki, 1964. Because this study was an observational study using a global open database (FAERS) with anonymized information and not involving treatment intervention or collection of human samples, informed consent was exempted.

\section{References}

1. "GHO |. By category | Overweight / Obesity." [Online]. Available: https://apps.who.int/gho/data/node.main.A896?lang=en. [Accessed: 23-Feb-2021].

2. “Products - Data Briefs. - Number 360 - February 2020." [Online]. Available: https://www.cdc.gov/nchs/products/databriefs/db360.htm. [Accessed: 23-Oct2020].

3. "The State of Obesity. 2020: Better Policies for a Healthier America - tfah." [Online]. Available: https://www.tfah.org/report-details/state-of-obesity-2020/. [Accessed: 23-Oct-2020].

4. Leblanc ES, O'Connor E, Whitlock EP, Patnode CD, Kapka T. Effectiveness of primary care-relevant treatments for obesity in adults: a systematic evidence review for the U.S. Preventive Services Task Force. " Ann Intern Med. Oct. 2011;155(7):434-47.

5. Sjöström L, Narbro K, Sjöström CD, Karason K, Larsson B, Wedel H, Lystig T, Sullivan M, Bouchard C, Carlsson B, Bengtsson C, Dahlgren S, Gummesson A, Jacobson P, Karlsson J, Lindroos A-K, Lönroth H, Näslund I, Olbers T, Stenlöf K, Torgerson J, Agren G. L. M. S. Carlsson, and Swedish Obese Subjects Study, "Effects of bariatric surgery on mortality in Swedish obese subjects. " N Engl J Med. Aug. 2007;357(8):741-52.

6. Buchwald H, "Avidor Y, Braunwald E, Jensen MD, Pories W, Fahrbach K, Schoelles K," Bariatric surgery: a systematic review and meta, 2004. 
7. Neff KJ, Olbers T, CW le Roux, "Bariatric surgery: the challenges with candidate selection, individualizing treatment and clinical outcomes.," BMC Med., vol. 11, p. 8, Jan. 2013.

8. "Who is a Candidate for Bariatric. Surgery? | Patients | ASMBS." [Online]. Available: https://asmbs.org/patients/who-is-a-candidate-for-bariatric-surgery. [Accessed: 23-Oct-2020].

9. Sargent BJ, Moore NA, "New central targets for the treatment of obesity.," Br. J. Clin. Pharmacol., vol. 68, no. 6, pp. 852-860, Dec. 2009.

10. Elangovan A, Shah R, Smith ZL, “Pharmacotherapy for Obesity-Trends Using a Population Level National Database.," Obes. Surg., Sep. 2020.

11. Rodgers RJ, Tschöp MH, Wilding JPH, “Anti-obesity drugs: past, present and future.," Dis. Model. Mech., vol. 5, no. 5, pp. 621-626, Sep. 2012.

12. Connolly HM, Crary JL, McGoon MD, Hensrud DD, Edwards BS, Edwards WD, Schaff HV, "Valvular heart disease associated with fenfluraminephentermine.," N. Engl. J. Med., vol. 337, no. 9, pp. 581-588, Aug. 1997.

13. James WPT, Caterson ID, Coutinho W, Finer N, Van Gaal LF, Maggioni AP, Torp-Pedersen C, Sharma AM, Shepherd GM, Rode RA, Renz CL, Investigators SCOUT, "Effect of sibutramine on cardiovascular outcomes in overweight and obese subjects.," N. Engl. J. Med., vol. 363, no. 10, pp. 905-917, Sep. 2010.

14. "Abbott Withdraws Sibutramine From Market." [Online]. Available: https://www.medscape.com/viewarticle/730155. [Accessed: 23-0ct-2020].

15. "Lorcaserin. (Belviq) Withdrawn From US Market Due to Cancer Risk." [Online]. Available: https://www.medscape.com/viewarticle/925253. [Accessed: 23Oct-2020].

16. Aagaard L, Hansen EH, "Information about ADRs explored by pharmacovigilance approaches: a qualitative review of studies on antibiotics, SSRIs and NSAIDs.," BMC Clin. Pharmacol., vol. 9, p. 4, Mar. 2009.

17. "Questions and Answers on FDA's Adverse Event Reporting System (FAERS). | FDA." [Online]. Available: https://www.fda.gov/drugs/surveillance/questions-and-answers-fdas-adverse-event-reporting-system-faers. [Accessed: 23-Feb-2021].

18. “Drugs@FDA. FDA-Approved Drugs.” [Online]. Available: https://www.accessdata.fda.gov/scripts/cder/daf/. [Accessed: 01-Dec-2020].

19. Lindquist M, StåhI M, Bate A, Edwards IR, Meyboom RH, "A retrospective evaluation of a data mining approach to aid finding new adverse drug reaction signals in the WHO international database.," Drug Saf, vol. 23, no. 6, pp. 533-542, Dec. 2000.

20. Aagaard L, Hallgreen CE, Hansen EH. Serious adverse events reported for antiobesity medicines: postmarketing experiences from the EU adverse event reporting system EudraVigilance." "Int J Obes. Aug. 2016;40(11):1742-7.

21. Aagaard L, Strandell J, Melskens L, Petersen PSG, Holme Hansen E, "Global patterns of adverse drug reactions over a decade: analyses of spontaneous

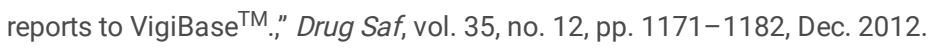

22. Wysowski DK, Swartz L, "Adverse drug event surveillance and drug withdrawals in the United States, 1969-2002: the importance of reporting suspected reactions.," Arch. Intern. Med., vol. 165, no. 12, pp. 1363-1369, Jun. 2005.

23. Khera R, Murad MH, Chandar AK, Dulai PS, Wang Z, Prokop LJ, Loomba R, Camilleri M, Singh S. Association of Pharmacological Treatments for Obesity With Weight Loss and Adverse Events: A Systematic Review and Meta-analysis. " JAMA. Jun. 2016;315(22):2424-34.

24. "Medications Target Long-Term. Weight Control | FDA." [Online]. Available: https://www.fda.gov/consumers/consumer-updates/medications-target-longterm-weight-control. [Accessed: 02-Jan-2021].

25. Srivastava G, Apovian CM. Current pharmacotherapy for obesity. Nat Rev Endocrinol. Jan. 2018;14(1):12-24.

26. Hampp C, Kang EM, Borders-Hemphill V, “Use of prescription antiobesity drugs in the United States.," Pharmacotherapy, vol. 33, no. 12, pp. 1299-1307, Dec. 2013.

27. Gadde KM, Allison DB, Ryan DH, Peterson CA, Troupin B, Schwiers ML, Day WW. Effects of low-dose, controlled-release, phentermine plus topiramate combination on weight and associated comorbidities in overweight and obese adults (CONQUER): a randomised, placebo-controlled, phase 3 trial. " Lancet. Apr. 2011;377(9774):1341-52.

28. Allison DB, Gadde KM, Garvey WT, Peterson CA, Schwiers ML, Najarian T, Tam PY, Troupin B, Day WW. Controlled-release phentermine/topiramate in severely obese adults: a randomized controlled trial (EQUIP). " Obesity (Silver Spring). Feb. 2012;20(2):330-42.

29. Velazquez A, Apovian CM. Updates on obesity pharmacotherapy. " Ann N Y Acad Sci. 2018;1411(1):106-19.

30. Tak YJ, Lee SY, “Anti-Obesity Drugs: Long-Term Efficacy and Safety: An Updated Review., World J. Mens. Health, Mar. 2020.

31. Daneschvar HL, Aronson MD, Smetana GW. FDA-Approved Anti-Obesity Drugs in the United States. " Am J Med. Mar. 2016;129(8):879.e1-6.

32. Yanovski SZ, Yanovski JA, "Long-term drug treatment for obesity: a systematic and clinical review.," JAMA, vol. 311, no. 1, pp. 74-86, Jan. 2014.

33. Bohula EA, Wiviott SD, McGuire DK, Inzucchi SE, Kuder J, Im K, Fanola CL, Qamar A, Brown C, Budaj A, Garcia-Castillo A, Gupta M, Leiter LA, Weissman NJ, White HD, Patel T, Francis B, Miao W, Perdomo C, Dhadda S, Bonaca MP, Ruff CT, Keech AC, Smith SR, Sabatine MS. B. M. Scirica, and CAMELLIA-TIMI 61 Steering Committee and Investigators, "Cardiovascular safety of lorcaserin in overweight or obese patients. " N Engl J Med. Sep. 2018;379(12):1107-17.

34. Kumar R, Ryan D, “Lorcaserin Departs, Leaving More Questions than Answers," Obesity (Silver Spring), vol. 28, no. 7, pp. 1167-1167, Jul. 2020.

35. Teng C, Walter EA, Gaspar DKS, Obodozie-Ofoegbu OO, Frei CR, "Torsades de pointes and QT prolongation Associations with Antibiotics: A Pharmacovigilance Study of the FDA Adverse Event Reporting System.," Int J Med Sci, vol. 16, no. 7, pp. 1018-1022, Jun. 2019.

36. "Liraglutide Injection. MedlinePlus Drug Information." [Online]. Available: https://medlineplus.gov/druginfo/meds/a611003.html. [Accessed: 24-Apr-2021].

\section{Figures}




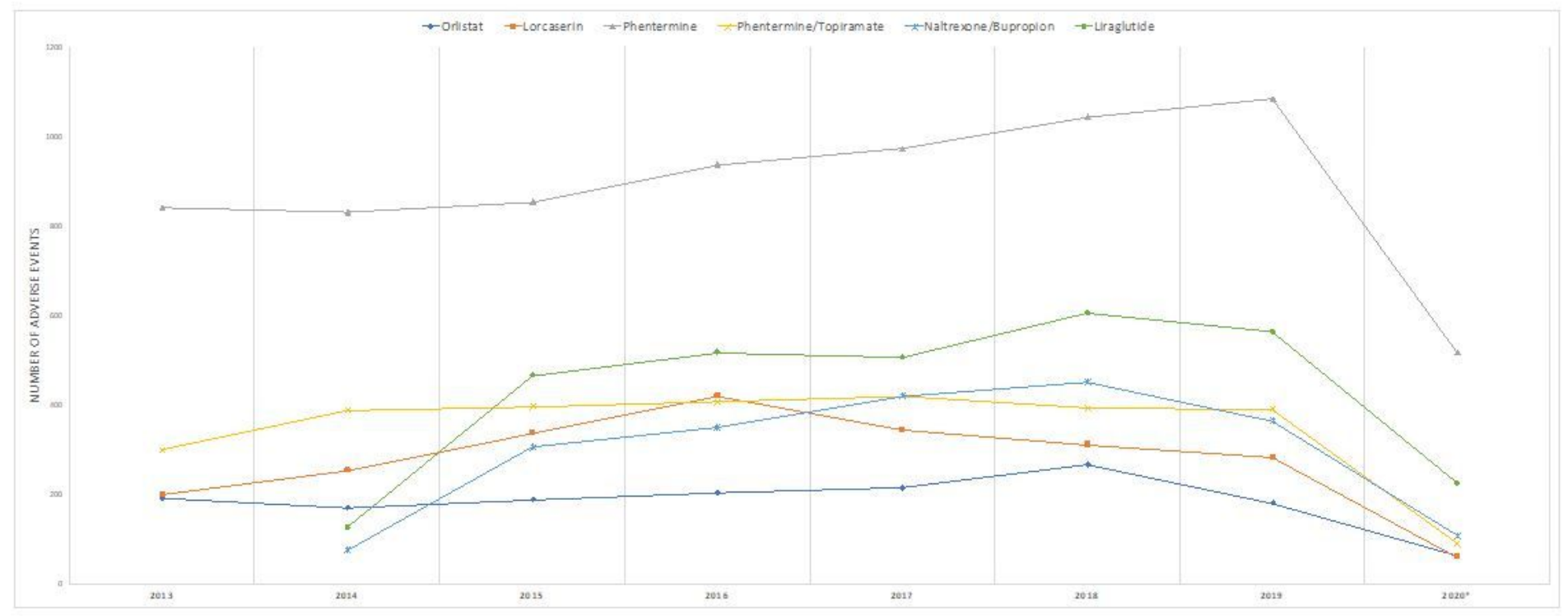

\section{Figure 1}

Trends of antiobesity medications reported adverse events: United States, first quarter of 2013 - second quarter of 2020, using the FDA's Adverse Event Reporting System (FAERS) database. *Only the second quarter of 2020 is included.

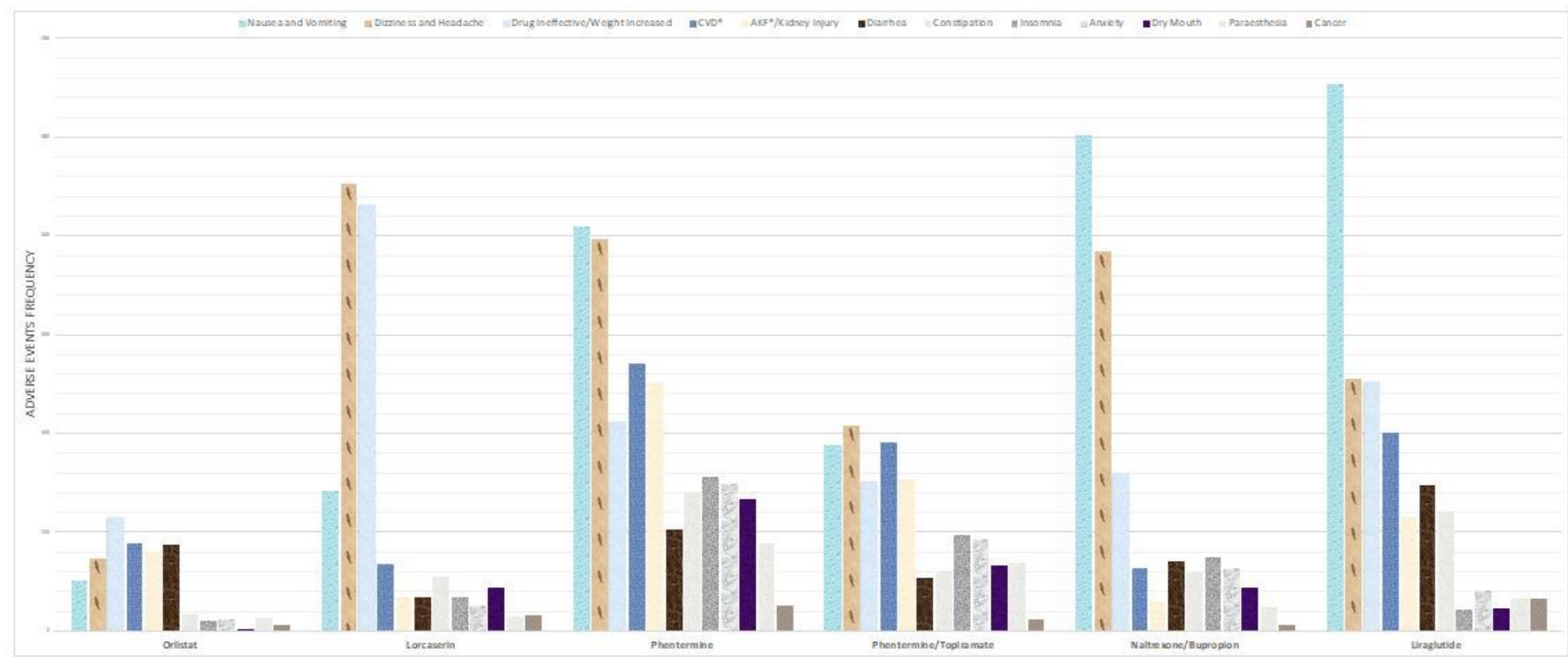

Figure 2

The most common reported adverse events associated with antiobesity medications: Using the FDA's Adverse Event Reporting System (FAERS) database 2013-2020. *CVD, cardiovascular disease. AKF, acute kidney failure. 


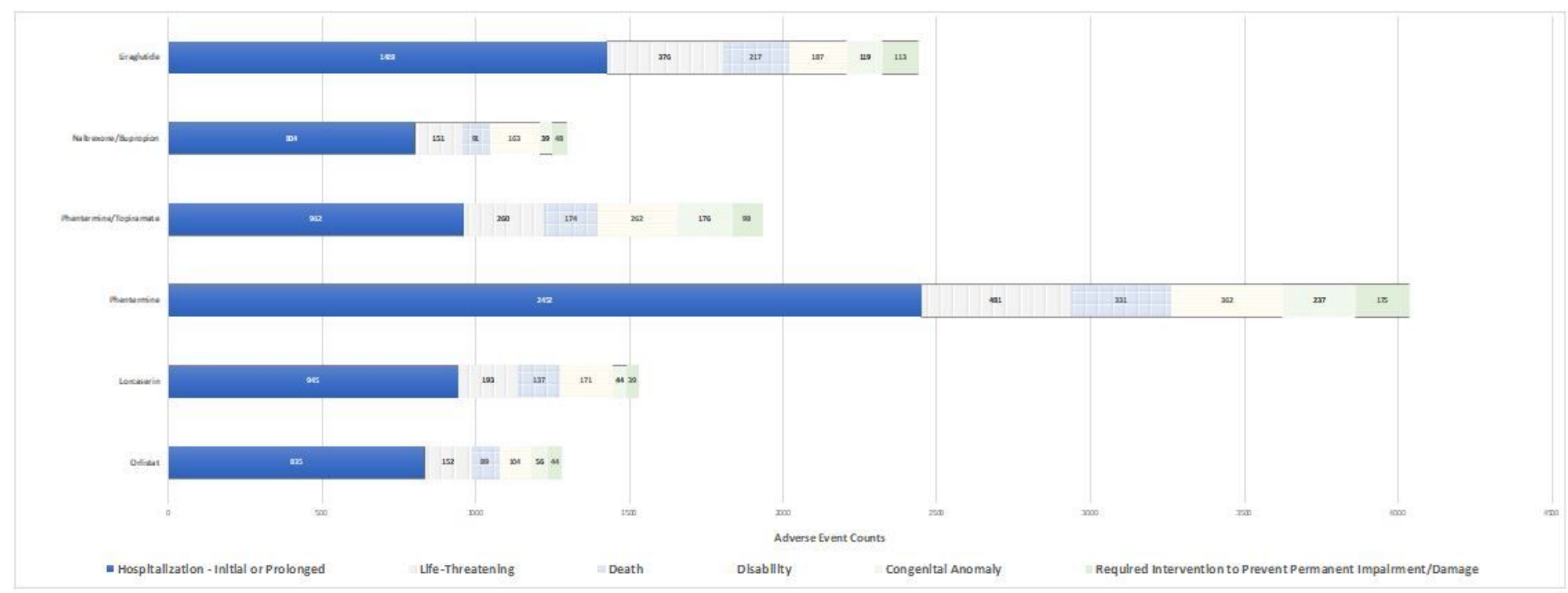

Figure 3

Trends of the type of hospitalization associated with antiobesity medications: Using the FDA's Adverse Event Reporting System (FAERS) database 20132020. 